\title{
277 El Parmak Replantasyonu: Demografik Özellikler ve Sonuçlarımız
}

\section{Hand Finger Replantation: Demographic Characteristics and Outcomes}

Hakan Çinal ${ }^{1}$,

Ensar Zafer Barın²,

Murat Kara²,

Kerem Yılmaz',

Harun Karaduman ${ }^{3}$,

İhtişam Zafer Cengiz ${ }^{4}$,

Oğuz Boyraz ${ }^{5}$,

Ömer Parıldar ${ }^{6}$,

Melih Çakaroğlu

Muhammed Revaha Kırtılıı,

Emrah Patat ${ }^{8}$,

Osman Enver Aydın

Önder Tan ${ }^{10}$

'Zonguldak Bülent Ecevit Üniversitesi, Tıp Fakültesi, Plastik

Rekonstrüktif ve Estetik Cerrahi AD, Zonguldak.
${ }^{2}$ Atatürk Universitesi, Tıp Fakültesi, Plastik Rekonstrüktif ve Estetik Cerrahi AD. Erzurum

${ }^{3}$ Yıldırım Beyazıt Üniversitesi, Ankara Şehir Hastanesi, Plastik Rekonstrüktif ve Estetik Cerrahi AD, Ankara

${ }^{4}$ Cukurova Universitesi, Tıp Fakültesi, Plastik Rekonstrüktif ve Estetik Cerrahi AD, Adana

${ }^{5}$ Mersin Üniversitesi, Tıp Fakültesi, Plastik Rekonstrüktif ve

Estetik Cerrahi AD, Mersin

${ }^{6}$ Akdeniz Üniversitesi, Tıp Fakültesi, Plastik Rekonstrüktif ve

Estetik Cerrahi AD, Antalya

Ankara Üniversitesi, Tıp Fakültesi, Plastik Rekonstrüktif ve

Estetik Cerrahi AD, Ankara

Izmir Katip Çelebi Universitesi, Atatürk Eğitim ve Araştırma Hastanesi, Plastik Rekonstrüktif ve Estetik Cerrahi AD, Izmir Aydın Adnan Menderes Üniversitesi, Tıp Fakültesi, Plastik

Rekonstrüktif ve Estetik Cerrahi AD, Aydın

${ }^{10} \mathrm{Özel}$ Muayenehane. Istanbul

Geliş Tarihi/Received: 18 Ocak 2020

Kabul Tarihi/Accepted: 9 Mart 2020

Yazışma Adresi: Hakan Cinal, Zonguldak Bülent Ecevit Universitesi, Tıp Fakültesi, Plastik Rekonstrüktif ve Estetik Cerrahi Anabilim Dalı, Zonguldak, Türkiye

e-posta: mdcinal@gmail.com

\section{ORCID}

Hakan Çinal

https://orcid.org/0000-0002-9797-5730

Ensar Zafer Barın

https://orcid.org/0000-0002-0380-8553

Murat Kara

Murat Kara

Kerem Yımaz

https://orcid.org/0000-0002-7844-6761

Harun Karaduman

https://orcid.org/0000-0003-2696-7255

Intişam Zafer Cengiz

https://orcid.org/0000-0002-9372-5830

Oğuz Boyraz

https://orcid.org/0000-0002-6201-1384

Ömer Parular

https://orcid.org/0000-0002-5239-0093

Melih Çakaroğlu

https://orcid.org/0000-0002-2710-9009

Muhammed Revaha Kırtıllı

https://orcid.org/0000-0002-5422-2210

Emrah Patat

https://orcid org/0000-0002-3307-5522

Osman Enver Aydın

Osman Enver Aydin -0002-3307-5522

Onder Tan org/0000-0002-5823-2774

Önder Tan

https://orcid.org/000-0002-5706-0069
Öz

Amaç: İlk parmak replantasyonundan günümüze mikrocerrahi teknik ve enstrümanların çok gelişmesine rağmen tatminkar sonuçlara ulaşılamamıştır. Yapılacak her çalışma, bizi ideal sonuca biraz daha yaklaştıracaktır. Bu hedef doğrultusunda deneyimlerimizi sunmayı amaçladık.

Hastalar ve Yöntem: Çalışmaya tek merkezde 2010-2019 yılları arasında, 243 olguda replante edilen 277 parmak dahil edildi. Çalışmada; hasta dosyalarından, ameliyat notlarından, fotoğraflardan ve replantasyon izlem formlarından hastalara ait demografik bilgiler, ameliyat notları ve klinik izlem bilgileri elde edildi. Bulgular: Olguların yaş ortalaması 28.4 yıl idi. Toplam başarı oranı \% 64.9 olarak bulundu. En sık ezilme, en az avülsiyon tipi ampütasyon gerçekleşti. En yüksek başarı oranı giyotin tipi yaralanmada oldu (\% 88.7). Hastanede yatış süresi ortalama 11.8 gün (1-77) olarak bulundu.

Sonuç: Replantasyon konusunda yapılacak yeni çalışmalar gelecekte başarıyı ve fonksiyonel geri kazanımı artıracaktır. En önemlisi, parmak ampütasyonuna neden olan etkenlerin önlenmesi ve sigara kullanımının azaltılması olacaktır.

Anahtar Kelimeler: Ampütasyon, el, mikrocerrahi, parmak, replantasyon

\section{Abstract}

Aim: Although the development of microsurgical techniques and instruments since the first finger replantation, satisfactory results have not been achieved. Every study will bring us closer to the ideal result. In line with this goal, we aimed to present our experience.

Patients and Methods: Replantations of 277 fingers of 244 cases were enrolled in this single center study between 2010-2019. Demographic information, surgical and clinical data were collected from patient files, operation notes, photograps and follow-up forms.

Results: Mean age was 28.4 years. Total succes rate was found as $64.9 \%$. Most frequent etiology of amputation was avultion and the least one was guillotine amputation. The most successive results rate was found as $88.7 \%$ in guillotine amputations. Mean hospital stay was 11.8 days (1-77days).

Conclusion: New studies on replantation will increase the success and functional recovery in the future. Most importantly, prevention of the factors that cause finger amputation and smoking will be.

Keywords: Amputation, hand, microsurgery, finger, replantation
Atıf yapmak için: Çinal $\mathrm{H}$, Barın EZ, Kara M, Yılmaz K, Karaduman $\mathrm{H}$ Cengiz IZ, Boyraz O, Parıldar Ö, Çakaroğlu M, Kırtıllı, Patat E, Aydın OE, Tan Ö. 277 El Parmak Replantasyonu: Demografik Özellikler ve Sonuçlarımız. Selcuk Med J 2020;36(2): 79-86

\section{GíRiş}

El parmakları vücudun en fonksiyonel parçalarından birisidir. İnsan onlarla tutar, dokunur, hisseder, çalışır ve üretir. Bu nedenle el parmaklarının travmatik ampütasyonu fonksiyonel ve kozmetik kayıplara neden olarak hastanın yaşamını önemli derecede etkiler. İlk parmak replantasyonundan (1) günümüze mikrocerrahi teknikler ve donanımlar çok gelişmiştir. Ancak buna paralel olarak yine gelişen teknoloji sayesinde parmak ampütasyonu sayısı, yaralanma çeşitiliği ve şiddeti de artmıştır. Kopan parmağı replante etme kararı, parçanın hayatta kalmasını etkileyen çok sayıda faktöre ve elde edilecek fonksiyonel-estetik sonuçlara bağııdır. Hastanın replantasyon ısrarı, özellikle rölatif endikasyonlarda ve fonksiyonel sonuç beklentisi yüksek olmayan durumlarda, cerrahın karar vermesinde etkili bir faktördür.

Daha önce yapılmış el parmak replantasyon serilerinde \% 49-92 arası başarı oranları raporlanmıştır (2-4). Replantasyon cerrahisinin başarısı; yaralanma mekanizması, iskemi süresi, sistemik hastalık varlığı gibi birçok faktörlere 
bağlı olarak değişmektedir. Çok sayıda parametreden etkilenen başarı oranını, daha yukarılara taşımak için çok daha fazla klinik çalışmaya intiyaç olduğu açıktır. Replantasyon cerrahisi ile ilgili yapılan yeni çalışmalar ve aktarılan deneyimler sayesinde daha doğru tedavi metotları gelişecek, sonuç olarak başarı oranı gittikçe artacaktır. Bu nedenle deneyimlerimizi sunmak, önceki çalışmalardaki verileri tartışmak için Türkiye'deki en geniş el parmak replantasyon serisini raporlamayı amaçladık.

\section{HASTALAR VE YÖNTEM}

Bu çalışma için Atatürk Üniversitesi Tıp Fakültesi Klinik Araştırmalar Etik Kurulu'ndan onay alınmıştır. (Tarih: 16.01.2020, Toplantı sayısı: 01, Karar no: 27) Tek merkezde, 2010-2019 yılları arasında yapılan tüm el parmak replantasyonlarını retrospektif olarak inceledik. Bu 10 yıllık çalışmaya metakarpofalangeal (MP) eklem ve distalinden yapılan el parmak replantasyonlarını dahil ettik. Replantasyon işlemi beş öğretim üyesi ve onların nezaretinde 4 . ve 5 . yıl asistanları tarafından gerçekleştirildi. Çalışmada; hasta dosyalarından, ameliyat notlarından, fotoğraflardan ve replantasyon izlem formlarından hastalara ait demografik, ameliyat ve klinik izlem bilgileri elde edildi.

Amputasyon seviyesi Tamai sınıflamasına göre gruplandırıldı (5). Tamai Zon 1 ve 2'yi oluşturan parmak ucu ampütasyonları için Yamano sınıflaması kullanıldı (6) (Tablo 1). Hastalar 0-12 yaş arası pediyatrik, 13-18 yaş arası genç erişkin, 19-59 yaş arası erişkin ve 60 yaş üzeri geriyatrik grup olarak kabul edildi. Olgular yaş, cinsiyet, etiyolojik neden, yaralanma mekanizması, etkilenen parmaklar, amputasyon seviyesi, iskemi süresi, sigara kullanımı, mikrocerrahi onarımlar, revizyon ve başarı oranları açısından değerlendirildi.

\section{Cerrahi Teknik}

Hastalar genel anestezi (GA), brakiyal pleksus blokajı (BPB) ve dijital blok anestezisi (DBA) altında ameliyat edildi. Parmak replantasyonu işleminde, kemik tespiti ve tendon onarımlarından sonra sırasıyla dijital arter-ven-sinir mikrocerrahi yöntemlerle onarıldı. Ameliyat sonrası 10 gün boyunca klinik olarak sıkı parmak perfüzyon takibi ve sıcak uygulama yapıldı. Sistemik düşük molekül ağırlıklı heparin, dekstran 40 (500 ml 8 saat infüzyon, 5 gün), antibiyotik ve antiinflamatuvar tedavi uygulandı. Ezilme ve avülsiyon tipi ampütasyonlarda $100 \mathrm{mg}$ asetil salisilik asit tablet günlük tedaviye eklendi. Zon 1 ampütasyonu olan hastalarda kemik tespitinden sonra genellikle sadece tek arter onarımı yapılabildi. Venöz yetmezlik durumunda replante parmağa medikal sülük uygulaması yapıldı ve/veya günlük hemogram takibi ile tırnak yatağı heparin ile kanatıldı.

Istatistiksel Analiz

İstatistiksel analizler Statistics for Social Sciences (SPSS) v16 paket program ile yapıldı. Gruplar arasındaki kategorik değişkenler Khi kare testi ile karşılaştırıldı. 0.05 'in altındaki p değerleri istatistiksel olarak anlamlı kabul edildi.

\section{BULGULAR}

Çalışma süresi boyunca 243 hastanın 277 el parmağına replantasyon yapıldı. Yaş ortalaması 28.4 yıl (1.5-74) olmak üzere en çok erişkin (\% 57.8) yaş grubu ameliyat edildi (Tablo 2). Toplam başarı oranımız \% 64.9 idi. Çoklu parmak ampütasyonu olan 25 hastanın replante edilen 59 parmağında (17 hastada 2, 7 hastada 3, 1 hastada 4 parmak) \% 49.1 başarı elde edildi. İstatiksel olarak anlamlı olmamakla birlikte $(p=0.326)$ en yüksek başarı $\% 70$ oranında geriyatrik grupta elde edildi. Hastaların 241'i (\% 87) erkekti. Erkek-kadın başarı oranı sırası ile \% 65.1 ve $\% 63.8$ olarak bulundu $(p=0.883)$. Hastanede yatış süresi ortalama 11.8 gündü (1-77 gün). Ampüte olan

Tablo 1. Tamai ve Yamano Sınıflandırması

\begin{tabular}{l} 
Tamai Sınıflaması \\
\hline Zon 1 - Distalden FDP insersiyosuna kadar \\
Zon 2 - FDP insersiyosundan DIP ekleme kadar \\
Zon 3 - DIP eklemden FDS insersiyosuna kadar \\
Zon 4 - FDS insersiyosundan MP eklem distaline kadar \\
Zon 5 - MP eklem ve proksimali \\
Parmak ucu ampütasyonları için Yamano Sınıflaması \\
Tip 1 - Giyotin tipi yaralanma \\
Tip 2 - Ezilme tarzı yaralanma (örneğin: testere) \\
Tip 3 - Ağır ezilme ve/veya avülsiyon yaralanması (örneğin: Makine veya kapıya sıkıştırma)
\end{tabular}

FDP: Flexor Digitorum Profundus DIP: Distal Interphalangeal FDS: Flexor Digitorum Superficialis MP: Metacarpophalangeal 
parmaklarda taraf üstünlüğü yoktu (sağ-sol, \% 49.950.1). En fazla işaret ve orta parmak replante edildi $(p=0.831)$. En sık zon 2 ve 3, en az zon 5 seviyesinden amputasyon gerçekleşti (Şekil). En yüksek başarı zon 4, en düşük başarı ise zon 2 bölgesinden olan ampütasyonlarda olmasına rağmen istatistiksel olarak anlamlı fark yoktu ( $p>0.05)$. Çift seviyeli ampütasyonu olan beş hastada \% 40 başarı oranı elde edildi. Erişkin grupta belirgin erkek cinsiyet üstünlüğü vardı
(\% 90.7). Yetişkin hastaların yarısından fazlası iş kazası ve tarım makineleri nedeni ile yaralanırken, pediyatrik ve geriyatrik grupta en sık etiyolojik neden yine tarım makineleri oldu (Tablo 3). En sık ezilme, en az avülsiyon tipi amputasyon gerçekleşti. En yüksek başarı oranı giyotin tipi yaralanmada elde edildi (\% 88.7) $(p=0.0001)$. BPB ve DBA altında yapılan replantasyonların başarı oranı, GA altında ameliyat edilenlere göre yaklaşık \% 15 (Tablo 2) daha yüksek

Tablo 2. Değişkenlerin replantasyon başarısı üzerine etkisi

\begin{tabular}{|c|c|c|c|c|c|c|c|c|}
\hline \multirow[b]{2}{*}{ Yaş } & & \multicolumn{2}{|c|}{ Başarılı } & \multicolumn{2}{|c|}{ Başarısız } & \multicolumn{2}{|c|}{ Toplam } & \multirow[b]{2}{*}{$\mathbf{P}$} \\
\hline & & $\mathbf{n}$ & $\%$ & $\mathbf{n}$ & $\%$ & $\mathbf{n}$ & $\%$ & \\
\hline & $<13$ & 41 & 57.7 & 30 & 42.3 & 71 & 25.6 & 0.326 \\
\hline & $13-18$ & 15 & 57.7 & 11 & 42.3 & 26 & 9.4 & \\
\hline & $19-59$ & 110 & 68.7 & 50 & 31.3 & 160 & 57.8 & \\
\hline & $>60$ & 14 & 70 & 6 & 30 & 20 & 7.2 & \\
\hline & Toplam & & & & & 277 & 100 & \\
\hline \multirow[t]{3}{*}{ Cinsiyet } & Erkek & 157 & 65.1 & 84 & 34.9 & 241 & 87 & 0.883 \\
\hline & Kadın & 23 & 63.8 & 13 & 36.2 & 36 & 13 & \\
\hline & Toplam & 180 & 64.9 & 97 & 35.1 & 277 & 100 & \\
\hline \multirow[t]{6}{*}{ Parmak } & Başparmak & 30 & 63.9 & 17 & 36.1 & 47 & 16.9 & 0.831 \\
\hline & İşaret parmağı & 57 & 67.1 & 28 & 32.9 & 85 & 30.7 & \\
\hline & Orta parmak & 35 & 59.3 & 24 & 40.7 & 59 & 21.3 & \\
\hline & Yüzük parmağı & 32 & 65.3 & 17 & 34.7 & 49 & 17.7 & \\
\hline & Küçük parmak & 26 & 70.3 & 11 & 29.7 & 37 & 13.4 & \\
\hline & Toplam & & & & & 277 & 100 & \\
\hline \multirow{4}{*}{$\begin{array}{l}\text { Yaralanma } \\
\text { mekanizması }\end{array}$} & & & & & & & & \\
\hline & $\begin{array}{l}\text { Giyotin } \\
\text { Avülsiyon }\end{array}$ & $\begin{array}{l}86 \\
34\end{array}$ & $\begin{array}{l}88.7 \\
52.3\end{array}$ & $\begin{array}{l}11 \\
31\end{array}$ & $\begin{array}{l}11.3 \\
47.7\end{array}$ & $\begin{array}{l}97 \\
65\end{array}$ & $\begin{array}{l}35 \\
23.5\end{array}$ & 0.0001 \\
\hline & Ezilme & 60 & 52.2 & 55 & 47.8 & 115 & 41.5 & \\
\hline & Toplam & & & & & 277 & 100 & \\
\hline \multirow[t]{4}{*}{ Anestezi } & Genel Anestezi & 106 & 59.9 & 71 & 40.1 & 177 & 63.9 & 0.108 \\
\hline & Brakiyal Pleksus Blokajı & 23 & 74.2 & 8 & 25.8 & 31 & 11.2 & \\
\hline & Dijital Blok Anestezisi & 50 & 72.4 & 19 & 27.6 & 69 & 24.9 & \\
\hline & Toplam & & & & & & 100 & \\
\hline \multirow{4}{*}{$\begin{array}{l}\text { İskemi süresi } \\
\text { (saat) }\end{array}$} & & & & & & & & \\
\hline & $<6$ & 112 & 86.9 & 17 & 13.1 & 129 & $\begin{array}{l}46.6 \\
36.5\end{array}$ & 0.0001 \\
\hline & $\begin{array}{l}6-10 \\
>10\end{array}$ & $\begin{array}{l}48 \\
20\end{array}$ & $\begin{array}{l}47.5 \\
42.5\end{array}$ & $\begin{array}{l}53 \\
27\end{array}$ & $\begin{array}{l}52.5 \\
57.5\end{array}$ & $\begin{array}{l}101 \\
47\end{array}$ & $\begin{array}{l}36.5 \\
16.9\end{array}$ & \\
\hline & Toplam & & & & & & 100 & \\
\hline \multirow{3}{*}{$\begin{array}{l}\text { Arter anastomoz } \\
\text { sayısı }\end{array}$} & & & & & & & & \\
\hline & 1 anastomoz & 134 & 64.7 & 71 & 35.3 & 201 & 72.5 & 0.490 \\
\hline & 2 anastomoz & 50 & 65.8 & 26 & 34.2 & 76 & 27.5 & \\
\hline \multirow{6}{*}{$\begin{array}{l}\text { Ven anastomoz } \\
\text { sayısı }\end{array}$} & & & & & & & & \\
\hline & 0 anastomoz & 44 & 67.7 & 21 & 32.3 & 65 & 23.4 & \\
\hline & 1 anastomoz & 61 & 64.2 & 34 & 35.8 & 95 & 34.6 & 0.36 \\
\hline & 2 anastomoz & 68 & 62.4 & 41 & 37.6 & 109 & 39.4 & \\
\hline & 3 anastomoz & 6 & 85.7 & 1 & 14.3 & 7 & 2.2 & \\
\hline & 4 anastomoz & 1 & 100 & 0 & 0 & 1 & 0.4 & \\
\hline Greft ile onarım & & 22 & 52.4 & 20 & 47.6 & 42 & 15.2 & 0.048 \\
\hline Sigara kullanımı & & 33 & 41.2 & 47 & 58.7 & 80 & 42.3 & 0.0001 \\
\hline \multirow[t]{4}{*}{ komplikasyon } & Vazospazm & 19 & 48.7 & 20 & 51.3 & 39 & 14.1 & 0.001 \\
\hline & Trombozis & 8 & 38.1 & 13 & 61.9 & 21 & 7.5 & \\
\hline & Damar çap farkı & 0 & 0 & 2 & 100 & 2 & 0.7 & \\
\hline & Bükülme & 0 & 0 & 2 & 100 & 2 & 0.7 & \\
\hline Revizyon & & 8 & 47.1 & 9 & 52.9 & 17 & 6.1 & 0.080 \\
\hline
\end{tabular}




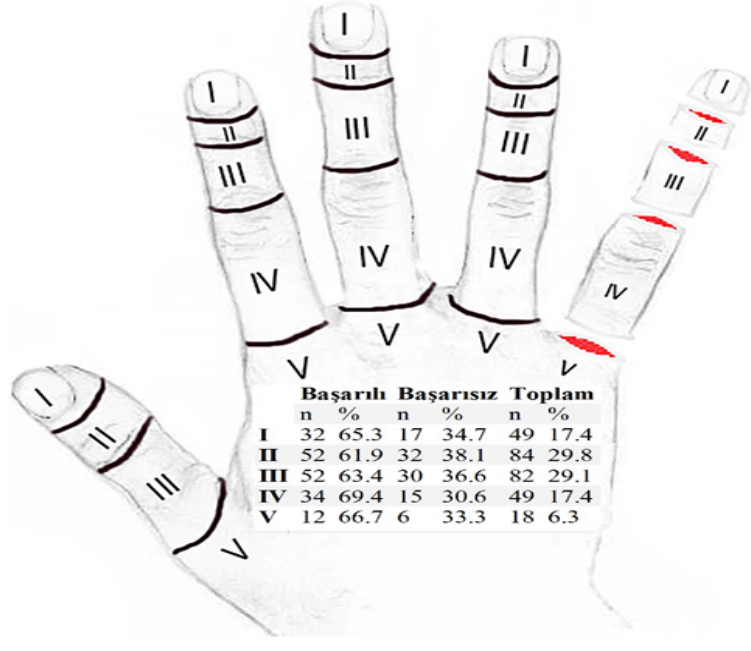

Şekil. El parmak replantasyonlarının Tamai sınıflamasına göre oranları.

bulunmasına rağmen istatiksel olarak anlamlı değildi $(p=0.108)$.

İskemisüresi6saatinaltında olan replantasyonlarda başarı oranı \% 86.9 iken altı saatten uzun olan parmaklarda başarı oranı dramatik olarak azaldı $(p=0.0001)$. Parmakların \% 72.5'ine tek, kalanına çift dijital arter anastomozu yapıldı. Çift arter onarılan parmaklarda daha fazla başarı sağlansa da istatiksel olarak anlamsız bulundu $(p=0.490)$. Üç ve üzeri ven onarımı yapılanlarda başarı artarken, ven onarım sayısı ile başarı arasında anlamlı fark bulunamadı $(p=0.360) .42$ parmakta damar onarımı greft ile yapıldı ve bu parmaklarda \% 52.4 başarı oranına ulaşıldı $(p=0.048)$. Olgular sigara içen ve içmeyen olarak iki gruba ayrıldı. İki grup arasında yaralanma tipi açısından anlamlı farklılık bulunmadı $(p=0.147)$. Bununla birlikte sigara içenlerde anlamlı derecede daha az başarı (\% 41.2) sağlandı $(p=0.0001)$. Ayrıca bu başarısızlık oranının, özellikle reperfüzyon süresi 6 saatten uzun olanlarda, sigara içmeyenlere göre daha hızlı düştüğü görüldü (Tablo 4,5).

İntraoperatif olarak 39 parmakta arteriyel spazm, 21 parmakta trombüs gelişti. Bu parmaklarda başarı oranı anlamlı olarak düşük bulundu (sırasıyla \% 48.7, \% 38.1) $(p=0.001)$. Arteriyel spazm gelişen 39 parmağın 27'si, trombüs gelişen 21 parmağın 15 'i ezilerek veya avülse olarak ampüte olmuştu. Replante edilen 17 (\% 6.1) parmağı revizyona almak zorunda kaldık. Bunlardan 8 tanesinde (\% 47.1) başarıya ulaştık ( $p=0.080$ ) (Tablo 2$)$. Tamai Zon 1 ve 2 olan parmak ucu replantasyonlarında, Yamano Tip 1 yaralanmalarda \% 93.6, Tip 2'de \% 46.6, Tip 3'de ise \% 46.2 başarı oranı elde ettik (Tablo 6).

\section{TARTIŞMA}

Parmak replantasyonu, mikrocerrahi disipline dayalı, ameliyat mikroskobu, mikrocerrahi alet, mikrodikişler gibi özel donanımlar gerektirir. Ayrıca işlem mikrocerrah, deneyimli hemşire ve yardımcı sağlık personelinden oluşan bir ekip işidir. Parmak replantasyonun başarısını etkileyen çok sayıda faktörün yanında, cerrahi deneyim ve sabır

Tablo 3. Parmak amputasyonlarının etiyolojik faktörleri

\begin{tabular}{|c|c|c|c|c|c|c|c|c|c|c|c|c|}
\hline \multirow[t]{2}{*}{ Etiyoloji } & \multicolumn{2}{|c|}{$\begin{array}{l}\text { Pediyatrik } \\
\text { grup }\end{array}$} & \multicolumn{2}{|c|}{$\begin{array}{l}\text { Genç erişkin } \\
\text { grup }\end{array}$} & \multicolumn{2}{|c|}{$\begin{array}{l}\text { Yetişkin } \\
\text { grup } \\
\text { Erkek }\end{array}$} & \multicolumn{2}{|c|}{ Kadın } & \multicolumn{2}{|c|}{$\begin{array}{l}\text { Geriyatrik } \\
\text { grup }\end{array}$} & \multicolumn{2}{|c|}{ Toplam } \\
\hline & $\mathbf{n}$ & $\%$ & $\mathbf{n}$ & $\%$ & $\mathbf{n}$ & $\%$ & $\mathbf{n}$ & $\%$ & $\mathbf{n}$ & $\%$ & $\mathbf{n}$ & $\%$ \\
\hline İş kazası & & & 3 & 11.5 & 60 & 41.1 & & & 2 & 10 & 65 & 23.4 \\
\hline Tarım makinesi & 29 & 41.4 & 7 & 27.2 & 15 & 10.3 & 1 & 6.7 & 6 & 30 & 58 & 20.9 \\
\hline Keskin alet & 16 & 22.9 & 7 & 27.2 & 22 & 15.1 & 4 & 26.4 & 2 & 10 & 51 & 18.4 \\
\hline Elektrikli alet & 4 & 5.7 & 3 & 11.3 & 19 & 12.6 & 1 & 6.7 & 5 & 25 & 32 & 11.6 \\
\hline Sıkışma & 11 & 15.8 & 1 & 3.8 & 5 & 3.5 & 2 & 13.4 & 1 & 5 & 20 & 7.2 \\
\hline Ağır cisim düşmesi & 4 & 5.7 & & & 10 & 6.9 & 1 & 6.7 & 2 & 10 & 17 & 6.1 \\
\hline Yüzük & & & 1 & 3.8 & 5 & 3.5 & 2 & 13.4 & 1 & 5 & 9 & 3.7 \\
\hline İpe dolanma & 1 & 1.4 & & & 4 & 2.8 & 1 & 6.7 & & & 6 & 2.1 \\
\hline Motorsiklet- & & & & & & & & & & & & \\
\hline bisiklet zinciri & 5 & 7.1 & 1 & 3.8 & 2 & 1.4 & & & 8 & 2.9 & & \\
\hline Hayvan saldırısı & & & & & 3 & 2.1 & 3 & 20 & 1 & 5 & 7 & 2.5 \\
\hline $\begin{array}{l}\text { Ateşli silah- } \\
\text { patlayıcı madde }\end{array}$ & & & 2 & 7.6 & 1 & 0.7 & & & & & 3 & 0.9 \\
\hline Trafik kazası & & & 1 & 3.8 & & & & & & & 1 & 0.3 \\
\hline Toplam & 70 & 100 & 26 & 100 & 146 & 100 & 15 & 100 & 20 & 100 & 277 & 100 \\
\hline
\end{tabular}


Tablo 4. Kümülatif Başarı Yüzdesi

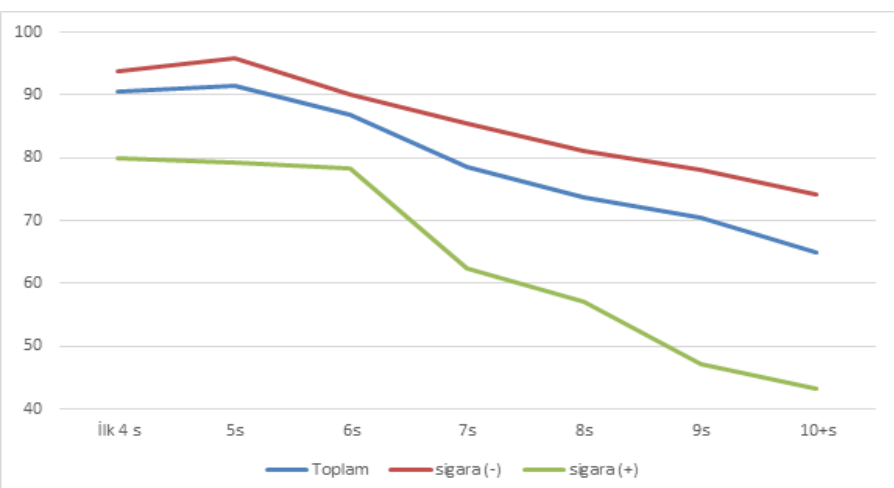

başarı oranını artıır. Özellikle rölatif endikasyonkontrendikasyonlar arasında keskin sınırlar olmadığından cerrahın isteği ve hastanın ısrarı endikasyonu genişletir ve bu durum başarı oranını düşürebilir. Daha önce yapılmış serilerde \% 49-92arası başarı oranları raporlanmıştır (2-4). Biz çalışmamızda \% 64.9 oranında başarı elde ettik. Hastaların dörtte birini pediyatrik grup oluşturdu. Çocuklarda damar çapının daha dar olması ve ven duvarının daha ince olması gibi teknik zorluklar nedeni ile başarı oranı daha düşüktür (7). İleri yaş, replantasyon cerrahisi için göreceli bir kontrendikasyondur. Çünkü yaşlı hastalarda eşlik eden kronik hastalık ve ateroskleroz oranı daha yüksektir $(4,8)$. Ek hastalığı olmayanlarda, yaşın tek başına riski artırmadığına dair çalışmalar da mevcuttur $(9,10)$. Bizde ise en düşük başarı oranı pediyatrik ve genç erişkin grupta bulunmasına rağmen, yaşın replantasyon başarısını istatiksel olarak anlamlı derecede etkilemediği görüldü. Çalışmamızda erkekkadın hastalar arasında başarı açııından anlamlı fark çıkmadı. Ayrıca otuz yaş ve üzeri hastalarda, başarı üzerine diğer etkili faktörleri gruplardan çıkararak sadece cinsiyetin replantasyon başarısı üzerine etkisini değerlendirdik. Sonuç olarak her ne kadar kadınlarda başarı oranı erkeklerden yaklaşık \% 10 daha fazla olsa da aradaki fark istatiksel olarak anlamlı bulunmadı $(p>0.05)$. Bu farkın anlamsız çıkmasında kadın olgu sayısının azlığının (20 olgu) etkili olduğunu
Tablo 5. Saatlik Başarı Yüzdesi

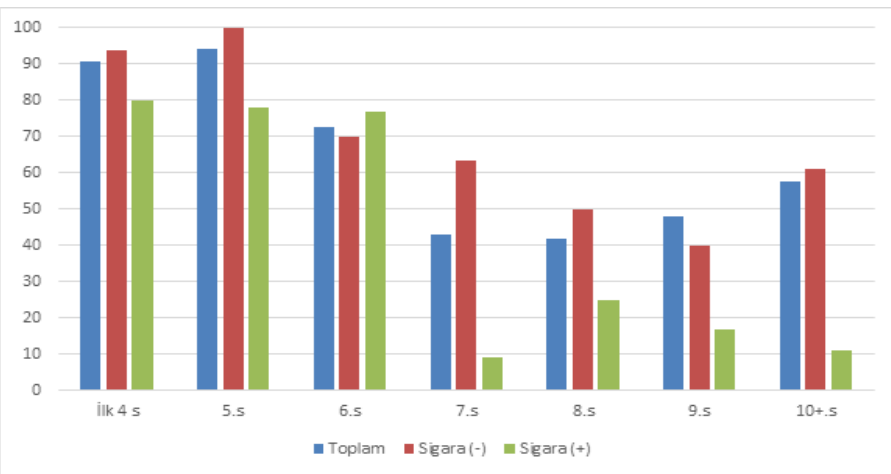

düşünüyoruz. Kadınlarda başarının oransal olarak daha yüksek çıkması, östrojen hormonunun koruyucu etkisiyle aterosklerozun daha az ve geç görülmesi (11) nedeniyle olabilir.

Etiyolojik faktörlerin sıklığı ve çeşitliliği her bölgenin sanayileşme, sosyo-ekonomik ve kültürel özelliklerine bağlı olarak değişmektedir. Tarım makinesi tüm yaş gruplarında önemli bir etiyolojik neden olarak karşımıza çıktı. Özellikle pediyatrik ve geriyatrik hasta grubunda bu faktör etiyolojinin en sık nedeniydi. Özellikle okul tatili ve hasat döneminin başladığı yaz aylarında çocukların tarım makineleri ile teması artmaktadır. Pediyatrik grupta, keskin aletin kesmesi ve parmağın kapı-çekmeceye sıkışması gibi ev kazaları sonraki nedenlerdi. Erişkin erkekler iş kazası açısından yüksek risk grubundadır (12). Erişkin grupta parmak ampütasyonu en sık iş kazaları nedeni ile oldu. İş sağlığı ve güvenliğine yönelik tedbirlere uyulması, denetlenmesi ve eğitimlerin artırılması bu tür kazaların azalmasını sağlayacaktır. Amputasyon seviyesi başarıyı etkileyebilir (13). Proksimale gittikçe damar çapının artması anastomozu daha kolaylaştırır, bu nedenle başarının daha yüksek olması beklenir. Çalışmamızda zon 4 ve 5 seviyesinde yapılan replantasyonların rakamsal olarak daha başarılı bulsak da istatiksel olarak önemli bir fark bulunamadı. Zon 1 seviye ampütasyonu ayrıca değerlendirmek gerekir. Pulpa seviyesindeki distal merkezi arter genellikle

Tablo 6. Parmak ucu replantasyonlarının Yamano sınıflamasına göre sonuçları

\begin{tabular}{|c|c|c|c|c|c|}
\hline \multirow[t]{3}{*}{ Yamano Sınıflaması } & \multicolumn{4}{|c|}{ Tamai Sınıflaması } & \multirow[t]{3}{*}{ Toplam (\%) } \\
\hline & \multicolumn{2}{|c|}{ Tamai Zon 1} & \multicolumn{2}{|c|}{ Tamai Zon 2} & \\
\hline & Olgu & Başarılı (\%) & Olgu & Başarılı (\%) & \\
\hline Yamano Tip 1 & 15 & $14 / 15(\% 93.3)$ & 32 & $30 / 32(\% 93.7)$ & 93.6 \\
\hline Yamano Tip 2 & 19 & $11 / 19(\% 57.8)$ & 41 & $17 / 41(\% 41.5)$ & 46.6 \\
\hline Yamano Tip 3 & 15 & $7 / 15(\% 46.6)$ & 11 & $5 / 11(\% 45.5)$ & 46.2 \\
\hline
\end{tabular}


mikrovasküler anastomoz için en uygun olanıdır. Tamai zon 1'de, merkezi arter tek başına parmak ucuna arteriyel dolaşım sağlar (14). Çünkü bu seviye parmağın en distal kısmı olması nedeni ile damar çapının en küçük olduğu bölgedir. Ayrıca anastomoz yapacak genişlikte ven bulunamayabilir (14). Ancak bu zonda kemik tespitinin kolay olması ve genellikle arter dışında mikrocerrahi gereksinimin olmaması operasyon süresini kısaltır(15). Ayrıca iskemiye maruz kalan dokunun minimum olması başarı oranını artırır. Dolayısıyla azami başarı, fonksiyonel ve kozmetik sonuç elde edilebilir. Olguların çoğunda onarılacak ven ve sinir bulunamadığından sadece arter onarımı yapıldı. Sadece arter anastomozu ile başarıyla yapılan parmak ucu replantasyon olguları rapor edilmiştir (15, 16). Sinir tamiri olmadan zon 1 replantasyonu yapılan hastalarda belirgin duyu kaybı olmadığı gösterilmiştir (15). Zon 1 seviyesinde replantın venöz yetmezliğe girmemesi için kemik tespitinin mümkün olan en ince telle yapılması gerekir. Kirchner-teli yerine uygun iğne ucu ile manuel olarak hızlı bir şekilde tespit yapılabilir. Ayrıca kemik tespitinin iyi yapılması, medüller kaviteden venöz drenajı artırır. Matsuda ve ark. (15) zon 1 seviyesinde yapılan replantasyonlarda ven anastomozu yapmakla yapmamak arasında fark olmadığını, ancak zon 2 seviyesinde ven onarımı yapılması gerektiğini belirtmişlerdir. Çalışmamızda zon 1 seviye replantasyon başarı oranımız diğer zonlara yakın bulundu. Bahsettiğimiz avantajları nedeniyle zon 1 seviye replantasyon başarı oranının diğer zonlara oranla daha yüksek olduğunu destekleyen çalışmalar da vardır $(8,18)$. Ayrıca parmak ucu ampütasyonlarında, diğer seviyelerde olduğu gibi etiyoloji başarı oranını etkiledi. Yamano Tip 1 ampütasyonlarda en yüksek başarıyı elde ederken, Tip 2 ve 3'te başarı oranımız oldukça düştü. Benzer bir çalışmada (14) daha yüksek başarı oranları elde edilmiştir. Ancak bu çalışmaya kıyasla ortalama iskemi süremizin daha uzun olmasından kaynaklandığını düşünüyoruz.

Çoklu parmak ampütasyonlarında iskemi süresi uzar ve cerrahi ekibin yorgunluğu da buna eklenince başarı şansı düşer $(19,20)$. Nitekim bu hasta grubunda başarı oranımız \% 49.1 oranında olmuştur. Çok seviyeli parmak replantasyonlarında daha fazla anastomoz gerekir. Bu nedenle iskemi süresi uzar. Ayrıca anastomoz sayısı arttıkça, vazospazm ve trombüs gibi cerrahi komplikasyonlar daha fazla görülür (21). En düşük başarı oranını bu grupta elde ettik. Çok seviyeli ampütasyonlar, replantasyon endikasyonları arasında sayılmamakta hatta bazı kaynaklarda göreceli kontrendikasyon olarak gösterilmektedir $(10,22)$. Yaralanma mekanizması birçok yazara göre başarıyı etkileyen en önemli faktördür $(8,10)$. Ezilme tipi yaralanmalarda intima hasarı meydana geldiğinden trombüs intimali çok yüksektir. Bu nedenle sağlam damara ulaşana kadar rezeksiyon yapmak gerekir. Özellikle makine-kayışa kaptırma gibi yüksek enerjili yaralanmalarda ezilmeye yanık da eşlik eder. Dolayısıyla rezeksiyon miktarı daha da artar ve çoğunlukla damar grefti gerektirir. Avülsiyon şeklinde olan ampütasyonlarda ise damarlarda olan hasar proksimale ve distale uzanmaktadır. Bu hasarın damar endotelinde, optik mikroskopta proksimal ve distal bölümde 8 mm'ye, elektron mikroskobunda ise 4 cm'ye kadar uzanabileceği gösterilmiştir (23). Bütün çalışmalarda en yüksek başarının elde edildiği yaralanma mekanizması, yapıların keskin cisimle koptuğu giyotin tipi ampütasyonlardır $(3,4,7,8,10,19,24)$. Dec ve ark.'Iarının (10) yaptığı bir meta analizde giyotin tipi yaralanmayı diğer ezilme ve avülsiyon tipi yaralanmalarla karşılaştırmışlardır (sırasıyla \% 91.4, \% 68.4 ve \% 66.3). Oruç ve ark.'larının (4) yaptığı çalışmada ise sırasıyla \% 81, \% 53 ve \% 36 başarı oranlarını elde ettiler. Bizim çalışmamızda ise giyotin tipi yaralanmada \% 88.7, ezilme tipi yaralanmalarda \% 52.2 ve avülsiyon tipi ampütasyonlarda ise \% 52.3 oranında başarıya ulaştık. Görüldüğü gibi yaralanma mekanizması başarı oranını yaklaşık \% 36 etkileyebilmektedir. Çalışmamızdaki olguların \% 65'inin avülsiyon ve ezilme tipi amputasyon olması ve replantasyon endikasyonlarımızı geniş tutmamız nedeniyle, toplam başarı oranımızın görece düşük olmasına sebep olduğunu düşünüyoruz. Ayrıca bir şehirden ziyade bir bölgeye hizmet veren Kliniğimizde, olguların çoğu şehir dışından gelmekte ve dolayısıyla iskemi süresi uzun olmaktadır. İskemi süresi replantasyon başarısını önemli ölçüde etkileyen etkenlerden biridir (19). Özellikle 10 saat ve üzeri iskemi süresi başarıyı düşürmektedir (4). Çalışmamızda ise 6 saatten daha kısa iskemi süresine sahip replantasyonlarda \% 86.9 oranında başarı elde ettik. Ancak 6 saatten sonra başarının dramatik olarak düştüğünü gözlemledik. Özellikle sigara içenlerde bu düşüş daha fazla oldu.

Replantasyon cerrahisi GA, BPB ve DBA altında yapılabilir. Ancak inhalasyon anestezisi sırasında kalp debisinin düşmesi, katekolamin deşarjı, aşırı ventilasyona bağlı hipokarbi, hipotermi gibi nedenler replante dokunun perfüzyonunu bozabilecek fizyolojik değişikliklere yol açabilir. BPB sempatik blok oluşturarak periferik vazospazmı önler, yaralanan 
parmakta perfüzyonu artırır. Ayrıca hastanın bilincinin açık olması, spontan solunumunun devam etmesi, havayolu reflekslerinin korunması, postoperatif dönemde analjezinin devam etmesi ve hastanın erken mobilizasyonu gibi önemli avantajları vardır. Ancak periferik nöropati, pnömotoraks, hematom, infeksiyon, sistemik toksik ve alerjik reaksiyonlar gibi riskleri de mevcuttur (25). DBA ise BPB'nın avantajlarının yanında hızlı uygulanabilmesi ve açlık ihtiyacı olmaması gibi nedenlerle cerrahiye olabildiğince erken başlanmasına olanak sağlar. Sonuç olarak iskemi süresini kısaltarak başarıyı artırabilir (26). Çalışmamızda istatiksel olarak anlamlı olmasa da, en düşük başarı oranını GA altında yapılan replantasyon işlemlerinde elde ettik.

Arter ve ven anastomoz sayısı arttıkça başarının artması beklenir (3). Ancak biz tek veya çift arter/ven anastomozu yapılan parmaklardaki başarı oranını birbirine yakın bulduk. Ancak üç veya dört ven anastomozu yapılan parmaklarda başarı oranının oldukça arttığını gördük. Greft kullanarak damar onarımı yapılan replantasyonların başarı oranı, toplam başarı oranımızın altında oldu. Çünkü greft anastomoz sayısını artırır. Sonuç olarak cerrahi komplikasyon, trombüs riski artar ve reperfüzyon süresi uzar. İntraoperatif vazospazm ve trombüs gelişen hastalarda başarı oranının bariz bir şekilde düştüğünü gördük. Ancak asıl cevaplanması gereken soru: vazospazm ve trombüs gelişen parmaklarda mı başarı oranı düşük yoksa zaten prognozu kötü parmaklarda mı daha sık vazospazm ve trombüs gelişiyor? Vazospazm ve trombüs gelişen parmakların çoğunun ezilerek veya avülse olarak ampüte olduklarından ikinci tezin daha doğru olduğunu düşünüyoruz. Ameliyat sırasında, damarda bükülme gelişen iki olguda bükülmenin düzeltilmesiyle ve damarsal çap farkı olan iki olguda ise küçük damarın oblik kesilmesiyle başarısızlığın önüne geçtik.

Sigara içmenin uzun süreli vazokonstriktif etkiye sahip olması nedeniyle başarısızlık riskini artırdığı tespit edilmiştir (27). Yapılan bir araştırmaya göre, düzenli sigara içicilerinde tek bir sigaranın içilmesi replante parmaktaki dolaşımı \% 4 oranında azaltmaktadır (28). Yine parmak replantasyonu üzerine yapılan başka bir çalışmaya göre, sigara içmeyenlerde içenlere oranla 11.8 kat daha fazla başarı elde edilmiştir (10). Nitekim bizim serimizde düzenli sigara içicilerinde başarı oranını ciddi manada düşük kaydettik. Başarı oranının parmağın reperfüzyon süresine göre değerlendirildiği grafikte, sigara içenlerde düşüşün özellikle ilk 6 saatten sonra daha dramatik olması özellikle dikkat çekiciydi.

\section{SONUÇ}

Parmak replantasyonu, gerektirdiği en gelişmiş mikrocerrahi donanımlara, en üst seviye cerrahi tecrübeye, en iyi şartlardaki uygulamalara ve ortaya çıkardığı yüksek maliyetlere rağmen sekel ile sonuçlanabilir. Bu da parmak yaralanmalarının önemli bir toplum sağlık sorunu olarak ortaya çıkmasına yol açmaktadır. Bu konuda yapılacak yeni çalışmalar gelecekte başarıyı ve fonksiyonel geri kazanımı artıracaktır. En önemlisi, parmak kopmasına yol açan kazaların önlenmesine ve sigara kullanımının azaltılmasına yönelik eğitimlerin ve tedbirlerin artırılması gerektiğini düşünmekteyiz.

Çıkar Çatışması: Çalışmada herhangi bir çıkar çatışması yoktur.

Finansal Çıkar Çatışması: Çalışmada herhangi bir finansal çıkar çatışması yoktur.

Yazışma Adresi: Hakan Çinal, Zonguldak Bülent Ecevit Üniversitesi, Tıp Fakültesi, Plastik Rekonstrüktif ve Estetik Cerrahi Anailim Dalı. 67600 - Zonguldak, Türkiye

Tel: + 903722612929 Mobil: + 905535525060 Fax : + 90 . 372. 2610155

E-mail: mdcinal@gmail.com

\section{KAYNAKLAR}

1. Komatsu S, Tamai S. Successful replantation of a completely cut-off thumb: Case report. Plast Reconstr Surg 1968;42:3747.

2. Morrison WA, McCombe D. Digital replantation. Hand Clin 2007;23:1-12.

3. Waikakul S, Sakkarnkosol S, Vanadurongwan V, et al. Results of 1018 digital replantations in 552 patients. Injury 2000;31(1):33-40.

4. Oruç M, Gürsoy K, Özer K, et al. Eight years of clinical experience with digit replantation: Demographic characteristics and outcomes. Ulus Travma Acil Cerrahi Derg 2017;23(4):311-6.

5. Tamai S. Digit replantation. Analysis of 163 replantations in an 11 year period. Clin Plast Surg 1978;5(2):195-209.

6. Yamano Y. Replantation of the amputated distal part of the fingers. J Hand Surg Am 1985;10:211-8.

7. Yildirim S, Calikapan GT, Akoz T. Reconstructive microsurgery in pediatric population-a series of 25 patients. Microsurgery 2008;28(2):99-107.

8. Kwon GD, Ahn BM, Lee JS, et al. The effect of patient age on the success rate of digital replantation. Plast Reconstr Surg 2017;139(2):420-6

9. Retrouvey $\mathrm{H}$, Solaja $\mathrm{O}$, Baltzer $\mathrm{HL}$. The effect of increasing age on outcomes of digital revascularization or replantation. Plast Reconstr Surg 2019;143(2):495-502.

10. Dec W. A meta-analysis of success rates for digit replantation. Tech Hand Up Extrem Surg 2006;10:124-9.

11. Kłosiewicz-Wasek B, Ceremuzynski L, Polonski $L$, et al. Association between carotid artery atherosclerosis and 
coronary artery disease in young females. Reference to sex hormone profile. Kardiol Pol 2008;66:127-32.

12. Largo TW, Rosenman KD. Michigan work-related amputations, 2008. J Occup Environ Med 2013;55(3):280-5.

13. Chiu HY, Shieh SJ, Hsu HY. Multivariate analysis of factors influencing the functional recovery after finger replantation or revascularization. Microsurgery 1995;16:713-7.

14. Dadaci $M$, Ince B, Altuntas Z, et al. Assessment of survival rates compared according to the Tamai and Yamano classifications in fingertip replantations. Indian J Orthop 2016;50(4):384-9.

15. Akyurek M, Şafak T, Kecik A. Fingertip replantation at or distal to the nail base: Use of the technique of artery-only anastomosis. Ann Plast Surg 2001;46:605-12.

16. Karagöz H, Turhan A, Bayram Y. Fingertip necrosis caused by bone fixation in case of the thumb distal phalanx replantation using the artery-only anastomosis. Turk Plast Surg 2011;19 (3):131-4.

17. Matsuda M, Chikamatsu E, Shimizu Y. Correlation between number of anastomosed vessels and survival rate in finger replantation. J Reconstr Microsurg 1993;9(1):1-4.

18. Ozcelik IB, Purisa $H$, Sezer İ, et al. The results of digital replantations at the level of the distal interphalangeal joint and the distal phalanx. Acta Orthop Traumatol Turc 2006;40(1):62-6.

19. Chia DS, Tay SC. A retrospective review of troubled replantations. Hand Surg 2015;20(1):127-32.
20. Demirtaş Y, Çiftci M, SöylemezF, etal. Çoklu replantasyonlarda başarıyı etkileyen faktörler. Turk Plast Surg 2008;16(1):55-6.

21. Dadacı M, Altuntaş Z, İnce B, et al. Succesful repair in multiple level digital artery injuries. Turk Plast Surg 2015;23(2):71-4.

22. Pederson WC. Replantation. Plast Reconstr Surg 2001;107:823-41.

23. Sakinsel A, Turgut G, Kuran İ, et al. Yüzük avülsiyon yaralanmasına bağlı ampüte parmakta replantasyon. ŞEH Tıp Bülteni 1996; 3(4):65-7.

24. Li J, Guo Z, Zhu Q, et al. Fingertip replantation: Determinants of survival. Plast Reconstr Surg 2008;122(3):833-9.

25. Bayar I, Demir C, Süğür T, et al. The use of neurostimulation with ultrasound-guided brachial plexus block: Does it increase success? Agri 2019;31:79-85.

26. Cinal $\mathrm{H}$, Tan Ö. Comparison of finger replantations performed with digital block anesthesia and general anesthesia methods. Dicle Med J 2019;46 (4):667-5.

27. van Adrichem LN, Hovius SE, van Strik $R$, et al. The acute effect of cigarette smoking on the microcirculation of a replanted digit, J Hand Surg 1992;17(2):230-4.

28. Van Adrichem LN, Hovius SER, Van Strik R, et al. The acute effect of cigarette smoking on the microcirculation of a replanted digit. J Hand Surg 1992;17A:230-4. 